\title{
A Comparative Study on the Marginal Fit of Zirconia Cores Manufactured by CAD/CAM and Copy Milling Methods
}

\section{Park $\mathrm{JH}^{1}$, Kwon $\mathrm{TK}^{2}$, Yang $\mathrm{JH}^{1}$, Han $\mathrm{JS}^{1}$, Lee $\mathrm{JB}^{1}$, Kim $\mathrm{SH}^{1}$ and Yeo IS ${ }^{1 *}$}

${ }^{1}$ Department of Prosthodontics, School of Dentistry and Dental Research Institute, Seoul National University, Daehak-ro, Jongno-gu, Seoul 110-749, South Korea ${ }^{2}$ Department of Dentistry, St. Vincent Hospital, Catholic University of Korea, Ji-dong, Paldal-gu, Suwon 442-723, South Korea

\begin{abstract}
Purpose: The marginal fit of zirconia cores that were produced by CAD/CAM and by copy milling systems was compared and analyzed to confirm the significance of the variation in dental technicians' skill between the two systems.

Materials and Methods: Using dental resin teeth and individual trays, 30 plaster casts were produced. Fifteen casts were assigned to be used with five different zirconia core manufacturing dental laboratories using the same CAD/ CAM system, which were designated as the CC group. The remaining 15 were assigned to be used with five different zirconia core manufacturing dental laboratories using also the same copy milling system and were designated as the CM group. The zirconia cores were fabricated and were cemented onto the casts. The vertical marginal opening was measured under an optical microscope at $75 x$ magnification. The measured vertical marginal discrepancies were analyzed using an independent sample t-test, and the significance of the vertical marginal gap value for each dental laboratory was analyzed by performing the Kruskal-Wallis test.
\end{abstract}

Results: The means and standard deviations for the marginal discrepancies of the CC and CM groups were found to be $102.73 \pm 29.73 \mu \mathrm{m}$ and $82.25 \pm 22.37 \mu \mathrm{m}$, respectively. The independent sample t-test showed a significant difference between the two systems; the CAD/CAM system showed a larger vertical marginal gap than the copy milling system. The Kruskal-Wallis test indicated that no significant distributional differences were found between the dental laboratories in either the CAD/CAM or the copy milling systems.

Conclusions: The copy milling system may produce more accurate zirconia restorations than the CAD/CAM system. The technician's skill of a copy milling system may not be a determining factor influencing the accuracy of a single zirconia core.

Keywords: CAD/CAM; Copy milling; Zirconia; Marginal gap; Marginal fit

\section{Introduction}

Due to continued interest in aesthetic dental restorations, studies of restorations with similar dental colors have continued along with those of dental materials and instruments with satisfactory strength. Although various all-ceramic restorations have been used in-clinic, it has been difficult to find a material that satisfies the requirements for both strength and aesthetics. Recently, zirconia has been recognized as an alternative solution for this issue, and its clinical application has been widely used [1-5]. Because of the high melting point of zirconia, it is mainly processed by a milling method. This milling technique is one of the two major systems for producing restorations, based on the methods of image scanning and milling: namely, the computer-aided design and manufacturing (CAD/CAM) system and the copy milling system [68]. The CAD/CAM system applies CAD onto the images acquired by scanning a die, which is cut by following the design using a milling machine. The sintering process occurs afterward and manufactures a coping with light-curing resin on a die that is then replicated by cutting and sintering the resin [6,9-16]. By applying the CAD/CAM system, a dental laboratory can save time in producing cores and benefit by producing consistent results, although the system requires very expensive instruments [7]. Conversely, the equipment required for the copy milling system costs less, but requires a significant amount of time for zirconia block cutting because of the manual handling required, which is considered to be highly dependent on the skill of the dental technician $[6,7,17]$. However, there have been no studies evaluating the technique sensitivity of a milling system by measuring the marginal gaps of restorations made by the system.

In our present study, a CAD/CAM system was compared with a copy milling system to determine the marginal fit-a value that is considered to be the most representative parameter of precision in prosthodontics-to evaluate the accuracy of each dental laboratory. Attempts were made to compare and analyze the marginal discrepancy between dental laboratories.

\section{Materials and Methods}

By replicating and cutting the preformed teeth in the dentiform, the maxillary left central incisor shape of the resin model tooth was produced and used as the original abutment tooth (D85DP-CHO.1, Nissin Dental Products, Inc., Kyoto, Japan). Approximately $1.0 \mathrm{~mm}$ widths of the shoulder at the marginal zone from the labial, palatal, mesial, and distal sides are shown in Figure 1.

After a master die was formed by adjusting the model tooth on a pattern resin (DuraLay, Reliance Dental Mfg. Co., Worth, IL), it was used as an impression template. Individual trays were prepared and used to take the impression in polyvinylsiloxane (Aqua Sil Ultra Monophase, DENTSPLY Caulk, Milford, DE). High strength dental stone (GC Fujirock EP, GC Europe N.V., Leuven, Belgium) was poured into the

*Corresponding author: In-Sung Yeo, DDS, MSD, PhD, Assistant Professor, Department of Prosthodontics, School of Dentistry and Dental Research Institute Seoul National University, 101 Daehak-ro, Jongno-gu, Seoul 110-749, South Korea, Tel: +82-2-2072-2661; Fax: +82-2-2072-3860; E-mail: pros53@snu.ac.kr

Received September 17, 2013; Accepted October 10, 2013; Published October 12, 2013

Citation: Park JH, Kwon TK, Yang JH, Han JS, Lee JB, et al. (2013) A Comparative Study on the Marginal Fit of Zirconia Cores Manufactured by CAD/CAM and Copy Milling Methods. Dentistry 3: 163. doi:10.4172/2161-1122.1000163

Copyright: $\odot 2013$ Park JH, et al. This is an open-access article distributed under the terms of the Creative Commons Attribution License, which permits unrestricted use, distribution, and reproduction in any medium, provided the original author and source are credited. 


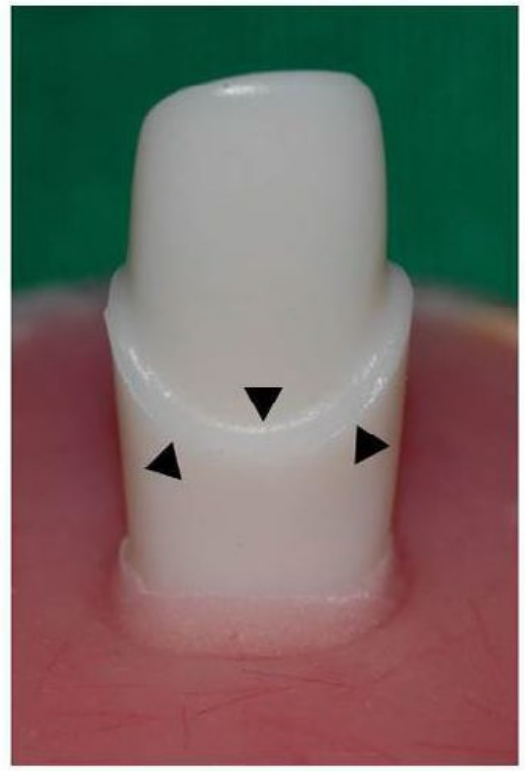

Figure 1: A prepared maxillary lett central Incisor model. I he root portion of this model was embedded in acrylic polymer. Note the uniform margin with 1.0-mm shoulder (black arrowheads).

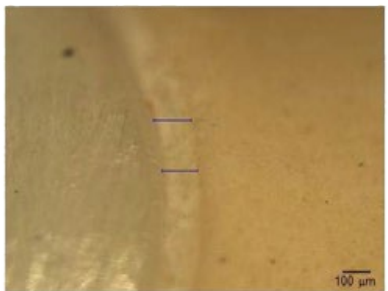

(a)

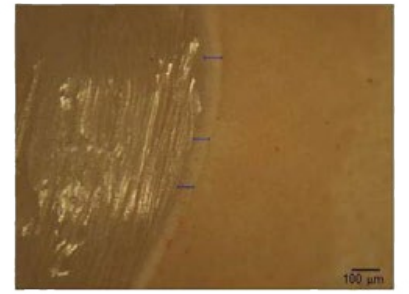

(b)
Figure 2: Marginal discrepancies of the zirconia cores that were made by (a) a CAD/CAM system and (b) a copy milling system. These light microscopic views show that the copy milling system produced more accurate zirconia cores than the CAD/CAM system did.

impressions to replicate 30 abutment tooth-shaped die sets. Three sets of the replicated dies were sent to each of the five dental laboratories using the same CAD/CAM system (assigned as groups A, B, C, D, and E). Three sets of the rest 15 dies were delivered to each of other five dental laboratories (assigned as groups a, b, c, d, and e), which used the same copy milling system. A total of 30 zirconia cores were made, with three cores manufactured by each of the 10 dental laboratories.

\section{Zirconia core fabrication}

In the case of the CAD/CAM group, the Everest system (Kavo, Biberach, Germany) was used. After the die scanning was completed, a cement space of $40 \mu \mathrm{m}$ was added from the incisal edge to $1 \mathrm{~mm}$ above the margin of the prepared dies. The zirconia blocks were cut and milled, and then the milled blocks were finally sintered to make zirconia cores.

In the case of the copy milling systems, die spacer was initially applied twice up to $1 \mathrm{~mm}$ above the margin for the cement space, while die hardener was applied on the margin. After the copings were made of light-curing resin, zirconia blocks were cut and milled with the Zirkonzahn` system (Zirkonzahn Gmbh, Bruneck, Italy) using the copy milling technique. Finally, the copy-milled blocks were sintered to make zirconia cores.

\section{Measurement of vertical marginal discrepancy}

Using a dual-cure resin cement (Rely X Unicem, 3M ESPE, Seefeld, Germany), 30 cores were cemented onto the dental stone dies under finger pressure due to clinical similarity. Only a chemical curing process was applied during the setting of the cement, without the light-curing procedure. While the core was in a cemented state, a marginal view of the core was observed using a stereoscopic microscope (SMZ-U, Nikon, Tokyo, Japan) at $75 \times$ magnification. Using the camera connected to the microscope and image analysis software (NIS-ELEMENTS, Nikon, Tokyo, Japan), 20 randomly selected points of the magnified marginal zone of each sample were photographed, and the vertical marginal gap value was measured (Figure 2).

The measurement points of each sample were limited to 20 photographed digital images. The marginal gap was measured at one to four measurement points in each image to acquire 50 total measurement points for each sample. The mean of the 50 vertical marginal gap values measured in each sample was set as the vertical marginal gap value. The 30 vertical marginal gap values that were acquired from the ten dental laboratories were used to calculate the mean vertical marginal gap values of the three samples from each dental laboratory.

\section{Statistical analysis}

The statistical significance of the differences in marginal fits between the CAD/CAM and copy milling systems was tested with an independent sample t-test. To test whether the vertical marginal gap created using each system was affected by the skills of dental laboratory technicians; the nonparametric Kruskal-Wallis test was performed. For all of the statistical tests, the level of significance was set to 0.05 .

\section{Results}

Table 1 shows the mean and standard deviation values of the

\begin{tabular}{|l|l|l|l|l|l|l|l|}
\hline $\begin{array}{l}\text { Die } \\
\text { number }\end{array}$ & Group CC & & & $\begin{array}{l}\text { Die } \\
\text { number }\end{array}$ & Group CM & & \\
\hline 1 & 152.51 & & & 16 & 96.00 & & \\
\hline 2 & 111.85 & Lab A & 141.42 & 17 & 88.46 & Lab a & 88.38 \\
\hline 3 & 159.91 & & & 18 & 80.67 & & \\
\hline 4 & 104.31 & & & 19 & 85.09 & & \\
\hline 5 & 98.99 & Lab B & 103.58 & 20 & 53.52 & Lab b & 65.77 \\
\hline 6 & 107.43 & & & 21 & 58.71 & & \\
\hline 7 & 99.64 & & & 22 & 62.87 & & \\
\hline 8 & 47.54 & Lab C & 75.99 & 23 & 74.31 & Lab C & 76.04 \\
\hline 9 & 80.80 & & & 24 & 90.93 & & \\
\hline 10 & 78.98 & & & 25 & 101.58 & & \\
\hline 11 & 103.66 & Lab D & 103.19 & 26 & 94.57 & Lab d & 89.59 \\
\hline 12 & 126.91 & & & 27 & 72.62 & & \\
\hline 13 & 86.00 & & & 28 & 79.11 & & \\
\hline 14 & 65.99 & Lab E & 89.46 & 29 & 141.08 & Lab e & 91.45 \\
\hline 15 & 116.39 & & & 30 & 54.17 & & \\
\hline Mean & 102.73 & & 102.73 & & 82.25 & & 82.25 \\
\hline SD & 29.73 & & 24.44 & & 22.37 & & 11.02 \\
\hline Table & & & & & & & \\
\hline
\end{tabular}

Table 1: Mean and standard deviation (SD) of the measured marginal fit values of the zirconia cores that were made by the CAD/CAM and copy milling systems. 
vertical marginal discrepancies. The mean and standard deviation values of all samples in the CC group and all samples in the CM group were found to be $102.73 \pm 29.73 \mu \mathrm{m}$ and $82.25 \pm 22.37 \mu \mathrm{m}$, respectively. The representative means and standard deviations of the measured marginal gap values for each dental laboratory were found to be 102.73 $\pm 22.44 \mu \mathrm{m}$ for the CC group and $82.25 \pm 11.02 \mu \mathrm{m}$ for the CM group (Table 1). The independent $\mathrm{t}$-test results showed a significant difference between the CAD/CAM and copy milling systems; the zirconia cores made by copy milling were significantly more accurate than those made by CAD/CAM $(\mathrm{P}=0.043)$. The Kruskal-Wallis test for the marginal fit found no significant differences among the dental laboratories $\mathrm{A}, \mathrm{B}$, $\mathrm{C}, \mathrm{D}$, and $\mathrm{E}$, which used the $\mathrm{CAD} / \mathrm{CAM}$ systems (the $\mathrm{CC}$ group, $\mathrm{P}=$ 0.13). In addition, there were no significant differences in marginal discrepancies among laboratories $\mathrm{a}, \mathrm{b}, \mathrm{c}, \mathrm{d}$, and e, which used the copy milling technique (the CM group, $\mathrm{P}=0.43$ ).

\section{Discussion}

This study found that the technician's skill was not a determining factor influencing the accuracy of a copy milling system in manufacturing a single zirconia core. Also, the copy milling system used in this study fabricated more accurate zirconia cores than the CAD/CAM system did. Considering that the manual handling by a dental technician is very important in the copy milling system, the variation in the marginal fits of the zirconia copings was anticipated to be larger among the dental laboratories using the copy milling system than those using the CAD/CAM system. However, the results of Kruskal-Wallis test in this investigation accepted the null hypothesis: there was no significant difference in marginal accuracy among the dental technicians when either a CAD/CAM or a copy milling system was used to make zirconia copings. The copy milling system may be appropriate for fabricating a zirconia restoration, considering the marginal accuracy and the dependency on the skill of technicians.

The marginal fit of fixed prosthodontics is an important factor in determining the success of the prostheses. An ideal marginal fit minimizes gingival stimulation, cement solubility, secondary caries, and discoloration of the marginal zone $[7,15]$. The clinically allowed maximum marginal gap has been reported to be $120 \mu \mathrm{m}$, although there is no clinically accepted clear standard for marginal fit [18]. Molin et al. also reported an appropriate marginal gap to be 50 to $100 \mu \mathrm{m}$ for resin cement to have an appropriate function in bonding [19]. Based on these suggestions, both the CAD/CAM and copy milling systems that were evaluated in this study produced zirconia cores that are clinically acceptable with regard to marginal accuracy. Several studies have discussed whether or not samples should be cemented before obtaining the marginal fit measurement $[5,14,20]$. Cementing had no significant effect on the vertical marginal gap in some previous studies, while others reported a significant increase in the marginal gap $[5,14,20]$. The effect of cementation on marginal accuracy is still considered to be controversial. The marginal gap was measured after cementing the samples in this study due to clinical similarity. Further investigations of the cementation effect are required.

There are various methods to measure the marginal gap of a fixed dental restoration. The direct observation that was used in this study is considered to be a useful and fast procedure that allows for the measurement of every restoration in the manufacturing process $[7,9,17]$.

However, the indistinct restoration margins, the locations of the samples, and the microscope positioning have a negative influence on accurate measurement by direct observation [7]. In the case of an over-contoured restoration, this direct observation method is limited in measuring the marginal discrepancy accurately, and the horizontal marginal misfit as well as the vertical one has to be included in the measurement [21]. Although a new method utilizing computer science has been recently introduced to evaluate the marginal fit in three dimensions, more studies are needed to determine an adequate methodology [22].

The suggested elements affecting the marginal accuracy of zirconia fixed prosthodontics include the manufacturing system, prosthodontic length, presence of a veneer, shape of the prosthodontic, and the years of service [11]. This study showed that a copy milling system produced more accurate zirconia frameworks than a CAD/CAM system when using a pre-sintered zirconia block. Pre-sintered blocks allow for faster and easier milling. However, shrinkage of 15 to $30 \%$ occurs due to sintering. This may increase the marginal gap of a restoration regardless of the milling technique used [15]. Kohorst et al. reported that the fully sintered zirconia and pre-sintered zirconia blocks exhibited absolute marginal errors of $58 \mu \mathrm{m}$ and 183 to $206 \mu \mathrm{m}$, respectively, in four-unit fixed prosthodontics [13]. Fully sintered zirconia requires no additional sintering. The material processing as well as the milling technique must be considered when evaluating the accuracy of a zirconia restoration.

\section{Conclusions}

The marginal fit of a zirconia coping for a single restoration in a copy milling system may be superior to that in a CAD/CAM system. This study, however, indicates that all of the zirconia copings made by both systems should be clinically acceptable, based on the criterion of the clinically acceptable marginal accuracy limit of $120 \mu \mathrm{m}$. The copy milling system may fabricate more accurate zirconia copings than the $\mathrm{CAD} / \mathrm{CAM}$ system without great dependence on the skill of dental technicians.

\section{References}

1. Triwatana P, Nagaviroj N, Tulapornchai C (2012) Clinical performance and failures of zirconia-based fixed partial dentures: a review literature. J Adv Prosthodont 4: 76-83.

2. Pelaez J, Cogolludo PG, Serrano B, Serrano JF, Suarez MJ (2012) A four-year prospective clinical evaluation of zirconia and metal-ceramic posterior fixed dental prostheses. Int J Prosthodont 25: 451-458.

3. Al-Amleh B, Lyons K, Swain M (2010) Clinical trials in zirconia: a systematic review. J Oral Rehabil 37: 641-652.

4. Koutayas SO, Vagkopoulou T, Pelekanos S, Koidis P, Strub JR (2009) Zirconia in dentistry: part 2. Evidence-based clinical breakthrough. Eur J Esthet Dent 4: $348-380$.

5. Martinez-Rus F, Ferreiroa A, Ozcan M, Pradies G (2013) Marginal discrepancy of monolithic and veneered all-ceramic crowns on titanium and zirconia implant abutments before and after adhesive cementation: a scanning electron microscopy analysis. Int J Oral Maxillofac Implants 28: 480-487.

6. Karl M, Graef F, Wichmann M, Krafft T (2012) Passivity of fit of CAD/CAM and copy-milled frameworks, veneered frameworks, and anatomically contoured, zirconia ceramic, implant-supported fixed prostheses. J Prosthet Dent 107: 232-238.

7. Karatasli O, Kursoglu P, Capa N, Kazazoglu E (2011) Comparison of the marginal fit of different coping materials and designs produced by computer aided manufacturing systems. Dent Mater J 30: 97-102.

8. Manicone PF, Rossi lommetti P, Raffaelli L (2007) An overview of zirconia ceramics: basic properties and clinical applications. J Dent 35: 819-826.

9. Song TJ, Kwon TK, Yang JH, Han JS, Lee JB, et al. (2013) Marginal fit of anterior 3-unit fixed partial zirconia restorations using different CAD/CAM systems. J Adv Prosthodont 5: 219-225.

10. Martinez-Rus F, Suarez MJ, Rivera B, Pradies G (2011) Evaluation of the absolute marginal discrepancy of zirconia-based ceramic copings. J Prosthet Dent 105: 108-114 
Citation: Park JH, Kwon TK, Yang JH, Han JS, Lee JB, et al. (2013) A Comparative Study on the Marginal Fit of Zirconia Cores Manufactured by CAD/ CAM and Copy Milling Methods. Dentistry 3: 163. doi:10.4172/2161-1122.1000163

11. Abduo J, Lyons K, Swain M (2010) Fit of zirconia fixed partial denture: a systematic review. J Oral Rehabil 37: 866-876.

12. Vagkopoulou T, Koutayas SO, Koidis P, Strub JR (2009) Zirconia in dentistry: Part 1. Discovering the nature of an upcoming bioceramic. Eur J Esthet Dent 4: 130-151.

13. Kohorst P, Brinkmann H, Li J, Borchers L, Stiesch M (2009) Marginal accuracy of four-unit zirconia fixed dental prostheses fabricated using different computeraided design/computer-aided manufacturing systems. Eur J Oral Sci 117: 319325 .

14. Gonzalo E, Suarez MJ, Serrano B, Lozano JF (2009) A comparison of the marginal vertical discrepancies of zirconium and metal ceramic posterior fixed dental prostheses before and after cementation. J Prosthet Dent 102: 378-384.

15. Beuer F, Aggstaller H, Edelhoff D, Gernet W, Sorensen J (2009) Marginal and internal fits of fixed dental prostheses zirconia retainers. Dent Mater 25: 94-102.

16. Att W, Komine F, Gerds T, Strub JR (2009) Marginal adaptation of three different zirconium dioxide three-unit fixed dental prostheses. J Prosthet Dent 101: 239-247.
17. Yeo IS, Yang JH, Lee JB (2003) In vitro marginal fit of three all-ceramic crown systems. J Prosthet Dent 90: 459-464.

18. McLean JW, von Fraunhofer JA (1971) The estimation of cement film thickness by an in vivo technique. Br Dent J 131: 107-111.

19. Molin MK, Karlsson SL, Kristiansen MS (1996) Influence of film thickness on joint bend strength of a ceramic/resin composite joint. Dent Mater 12: 245-249.

20. Borges GA, Faria JS, Agarwal P, Spohr AM, Correr-Sobrinho L, et al. (2012) In vitro marginal fit of three all-ceramic crown systems before and after cementation. Oper Dent 37: 641-649.

21. Holmes JR, Bayne SC, Holland GA, Sulik WD (1989) Considerations in measurement of marginal fit. J Prosthet Dent 62: 405-408.

22. Kim KB, Kim JH, Kim WC, Kim HY (2013) Evaluation of the marginal and internal gap of metal-ceramic crown fabricated with a selective laser sintering technology: two- and three-dimensional replica techniques. J Adv Prosthodont 5: 179-186. 